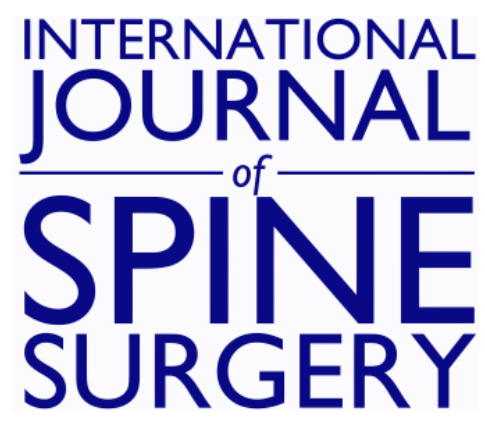

\title{
Treatment of contained lumbar disc herniations using radiofrequency assisted micro-tubular decompression and nucleotomy: four year prospective study results
}

Stefan Hellinger

Int J Spine Surg 2014, 8 ()

doi: https://doi.org/10.14444/1024

http://ijssurgery.com/content/8/24

This information is current as of April 26, 2023.

Email Alerts Receive free email-alerts when new articles cite this article. Sign up at: http://ijssurgery.com/alerts 


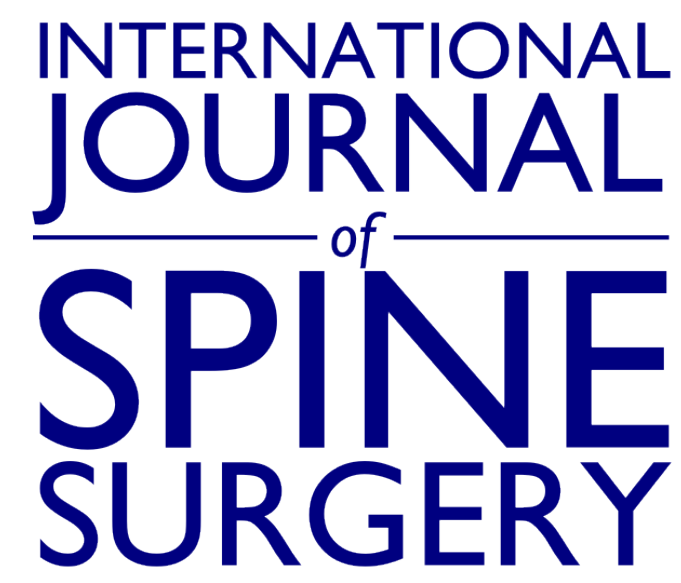

This article generously published free of charge by the International Society for the Advancement of Spine Surgery.

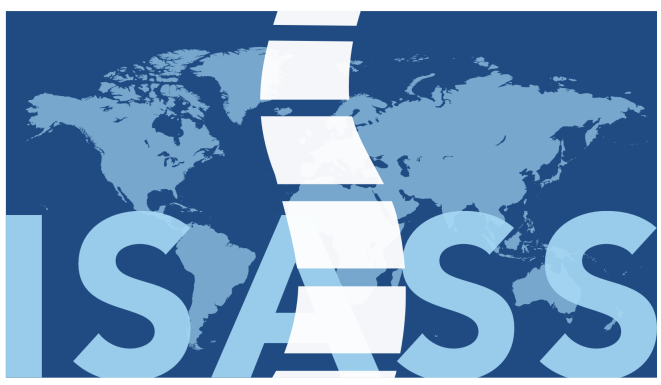

INTERNATIONAL SOCIETY for the ADVANCEMENT of SPINE SURGERY 


\section{Treatment of contained lumbar disc herniations using radiofrequency assisted micro- tubular decompression and nucleotomy: four year prospective study results.}

Stefan Hellinger, MD

ISAR Clinic Munich, München, Germany

\section{Abstract}

\section{Background}

Patients with radiculopathy caused by contained disc herniations are less likely to have good outcomes following discectomy surgery than patients with disc herniations that are not contained. The author presents his 4-year results from a prospective trial regarding the efficacy and safety of a tubular transforaminal radiofrequency-assisted manual decompression and annulus modulation of contained disc herniations in 58 patients.

\section{Methods}

Fifty-eight patients with lumbar radiculopathy due to a contained disc herniation were enrolled in a prospective clinical study. Visual analog scores (VAS) for back pain and leg pain, quality of life assessment, Macnab criteria, and SF-12 were collected from patients before treatment, at 2-years and 4-years post-treatment.

\section{Results}

At 4 years, results were obtained from 47 (81\%) of patients. Compared to mean pretreatment assessments, mean 4-year VAS for back pain improved from 8.6 to 2.3 points, and mean VAS for leg pain improved from 7.8 to 2.3. Eighty-three percent of respondents reported that they were "satisfied" or "very satisifed" with their quality of life at 4-years as per SF-12. At 4 years, recurrence was noted in $3(6.4 \%)$ of respondents and no complications were reported. 


\section{Conclusions}

The 2-year and 4-year study results are nearly identical, suggesting durable benefit out to 4 years. These results also suggest that in carefully selected patients with sustained contained disc herniations who have failed conservative treatments, manual decompression combined with radiofrequency-assisted decompression and annulus modulation are very likely to have good outcomes 4 years post-treatment.

keywords: discectomy, nucleotomy, contained disc, disc decompression, back pain, degenerative disc disease, microdiscectomy Volume 8 Article 24 - Endoscopic \& Percutaneous Special Issue doi: 10.14444/1024

\section{Introduction}

Disc abnormalities causing low back and/or leg pain (lumbar radiculopathy) are associated with enormous costs to society because they are extremely common and potentially debilitating. Approximately eighty percent of the population of industrial societies will be affected during their lifetime. ${ }^{1}$ Over the last several years, the surgical treatment of lumbar disc abnormalities has dramatically increased worldwide, with wide variation among regions attributed to (among other factors) differences in reimbursement, technology, and culture. .,3 $^{2,3}$

The increasing number of spinal surgeries is related to several factors including aging populations and more sensitive diagnostic tools. ${ }^{4}$

Common spinal disorders of back and leg pain, are due to degeneration of lumbar vertebral discs. Painful abnormality of discs is usually caused by herniation of the nucleus pulposus due to inflammation and/or compression of nerves. Fortunately, sixty to eighty percent of patients with acute painful disc herniations get better within six to twelve weeks without treatment. ${ }^{5,6}$ Among those who do not improve, conservative treatments often succeed in getting most patients back to work or other related activities. ${ }^{7,8,9}$

Contained disc herniations are thought to cause leg and/or back pain when the nerve roots become irritated by nucleus material within the posterior annulus. Beside anatomical and patholgical studies this has been demonstrated with endoscopic visualization by $\mathrm{T}$. Yeung. ${ }^{10}$ Disc herniations cause back and/or leg pain when a spinal nerve root becomes inflamed and/or compressed as it passes adjacent to the herniated disc. Clinical findings linked to disc herniations have significant symptoms due to different patho etiologies. The etiologies of disc pain, versus radicular pain, versus pseudo-radicular pain are not clearly understood. ${ }^{11,12,13,14,15}$

In recent years, minimal invasive techniques have emerged to treat patients diagnosed with disc herniations that cause both back and/or leg pain. They are intended to relieve pain or improve a neurological deficit causing functional limitations. The concept is to reduce tissue damage, scar tissue formation, and nerve root irritation while achieving good clinical outcomes when compared to conventional surgery. The goal of all these techniques is to close the gap between failed conservative treatment and open surgery, especially for contained herniated discs. ${ }^{16,17,18,19,20,21,22,23,24,25,26,27}$ 
Every technique should be evaluated and compared to the results of the existing standards and should focus on causing less trauma, less scarring in the epidural space which may become clinically symptomatic. ${ }^{28,29,30,31}$

The treatment studied and under review is a microtubular discectomy system indicated to treat patients suffering from: intractable back and/or leg pain, numbness, and/or cramping in the legs; secondary to a diagnosis of a symptomatic disc herniation with integrity of the posterior ligament while not responding to conservative treatment.

This procedure combines multiple treatment options that include manual discectomy augmented by radiofrequency-assisted nucleus ablation, annulus modulation and irrigation of the disc.

The purpose of this study is to investigate the long term outcomes of this microtubular procedure compared to published long term results of standard discectomy techniques. Similar outcomes from surgery for contained hernias are still not universally achieved due to their challenging nature. ${ }^{32}$

With this technique the hope was to show outcomes that were at a minimum equivalent to open surgery for cases of contained hernias, while causing less trauma to the patient.

\section{Materials and Methods}

All surgeries were performed by one surgeon between 2006 and 2008. 58 patients were enrolled in this prospective cohort outcome evaluation study. The study was discussed and approved by an internal commission from the hospital to check GCP practise. The average age of the 47 participating patients at the time of the index procedure was 43 years; range 24-67 years. 15 (32\%) were female, 32 (68\%) were male. Sixty-nine levels were treated during the index procedure. The number of procedures per level are as follows: L1-2 ( $n=1)$, L2-3 ( $n=1)$ L3-4 $(n=5)$, L4-5 ( $n=31)$, L5-S1 $(n=31)$.

\section{Inclusion criteria}

Inclusion criteria included concordant symptoms (leg, buttock, or groin pain with a VAS $>5$, numbness and/or cramping, with or without back pain) caused by a contained protruded lumbar disc (with an intact annulus fibrosis) or sometimes bulging black disc confirmed by imaging studies (MRI and/or CT). The precondition for a contained hernia was defined as: slipped nucleus material was within an intact outer annulus or a capsule composed of the outer annulus and the posterior longitudinal ligament, independent from the size of the protrusion but not in direct contact with epidural tissue shown in the images. Further in most cases a discography was performed prior to the surgery to exclude cases with epidural leakage of contrast, though a discography in of itself was determined not to be necessary in order to be part of the study and not used to confirm the source of the pain. The important point was that annular integrity was shown.

All patients signed an informed consent. Patients aged 18 to 68 years old were enrolled. 58 patients who met the inclusion criteria were treated with the same technique by a single surgeon (author) at one institution over the course of 18 months. These patients were followed out to two years and four years after the index procedure. ${ }^{33}$ 
Although no minimum duration of symptoms was established as a criterion for inclusion, in each case, the treating surgeon determined that not only were the symptoms of sufficient duration to warrant surgical intervention (usually, at least six weeks) but that the patients had also demonstrated failure to respond to conservative treatments (including but not limited to documented treatment by a licensed physical therapist experienced in treating disc herniations, and a minimum of at least two trials of epidural steroid injections).

\section{Exclusion criteria}

Exclusion criteria included patients who exhibited any of the following: progressive neurological deficits, sequestrations of HNP, severe stenosis, fracture, tumor, severe disc degeneration, disc collapse $>50 \%$, clinical evidence of cauda equina syndrome, and fixed motor deficit. Patients with segmental instability shown by advanced osteochondrosis or spondylosis (Modic signs II or more) or listhesis were not considered (Table 1).

\begin{tabular}{|c|c|}
\hline INCLUSION CRITERIA & EXCLUSION CRITERIA \\
\hline $\begin{array}{l}\text { concordant clinical signs to CT; MRI positive SLRT, axial pain, coughing, } \\
\text { sensory signs }\end{array}$ & progressive neurological deficits \\
\hline VAS $>5$ leg and back pain & $\begin{array}{l}\text { extruded, sequestrated herniation } \\
\text { decompression) }\end{array}$ \\
\hline symptomatic contained disc herniation & severe stenosis \\
\hline discogenic back pain & severe degeneative disc disease with end stage collapse $>50 \%$ \\
\hline $\begin{array}{l}\text { herniation by posterior ligament not greater than } 1 / 3 \text { the sagital diameter of } \\
\text { the spinal channel }\end{array}$ & activated osteochondritis, fracture, tumor, discitis \\
\hline 6 weeks failed conservative treatment & cauda equina syndrom \\
\hline no leakage of contrast/dye into the spinal channel during discography & fixed motor deficit \\
\hline slight neurological deficits & oversegmental instability - spondylolisthesis \\
\hline
\end{tabular}

The patients were evaluated pre-surgery, post-surgery, at 1 and 6 weeks by the surgeon to control surgery related complications as well as at 3,12 and 24 months by questionnaire.

Out of the total population from an earlier investigation at 2 years, all of the patients who were fluent in German $(\mathrm{N}=58)$ were enrolled in this $>4$ year prospective cohort outcome evaluation study by an independent research organization.

Questionnaires sent to these patients were based upon the current life situation of the patients regarding the past 4 weeks prior to the follow-up after 4 years postoperative and evaluated the following parameters: (a) individual analysis of complications (b) recurrence (c) back and leg pain according to a 0 (no pain) to 10 point (unbearable pain) VAS scale (d) subjective patient satisfaction; grading the results of the operation as: excellent, good, fair or unsatisfied (e) subjective grading of sensibility disturbance: Lower Extremity Paresthesias (f) subjective grading of leg strength: Lower Extremity Strenght (g) bodily capacity according to Macnab : Lifetime Satisfaction, (h) SF-12. 


\section{Surgical Technique}

Procedures were performed via posterolateral approach, using 1\% lidocaine at the entry point, $0.5 \%$ Mecaine (Marcaine) near the facet (patients were positioned either prone or in lateral decubitus position - symptomatic side up). Fluoroscopic imaging was used to measure and mark an entry point on the skin so that the posterolateral annulus fibrosis at the affected level could be targeted via a transforaminal trajectory. Sterile preparation and draping of the skin incorporated the entry site, and this area was infiltrated with local anesthetic. A 16G $\times 8$ inch needle is passed under sequential fluoroscopic guidance into the annulus fibrosis. The general target is to place the tip of the needle at the inner pedicle line in A/P fluoroscopic imaging, while at the same time be in the posterior $1 / 3$ of the disc in Lateral fluoroscopic imaging. The stylet is removed and a flexible, blunt guide wire is passed through the needle and beyond the needle tip into the nucleus pulposus. The needle is removed leaving the guide wire in place. Once this step is completed, a dilator is passed over the guide wire and a microtubular system is advanced over the dilator on the outer annulus. With the microtubular system in a fixed position against the annulus, the dilator is removed and a trephine is used to perform an annulotomy over the slipped nucleus. All of these steps were performed with fluoroscopic imaging in awake patients to provide feedback to the surgeon. Patients were instructed to notify the surgical team if they experienced any pain or paresthesia during the procedure. In order to avoid nerve root irritation, patients were frequently questioned during the procedure about any sign that might be interpreted as an indication of pain.

The cannula can be fixed using a depth stop and an initial decompression of approximately one cubic centimeter of intradiscal nucleus material is performed using a pituitary grasping forceps. This is followed by inserting the Trigger-Flex Bipolar System device to ablate the nucleus using high-frequency-low temperature radio energy. This special waveform produces controlled localized heat that ablates the nucleus material and further helps free up herniated disc material that can be removed with the pituitary grasping forceps. 


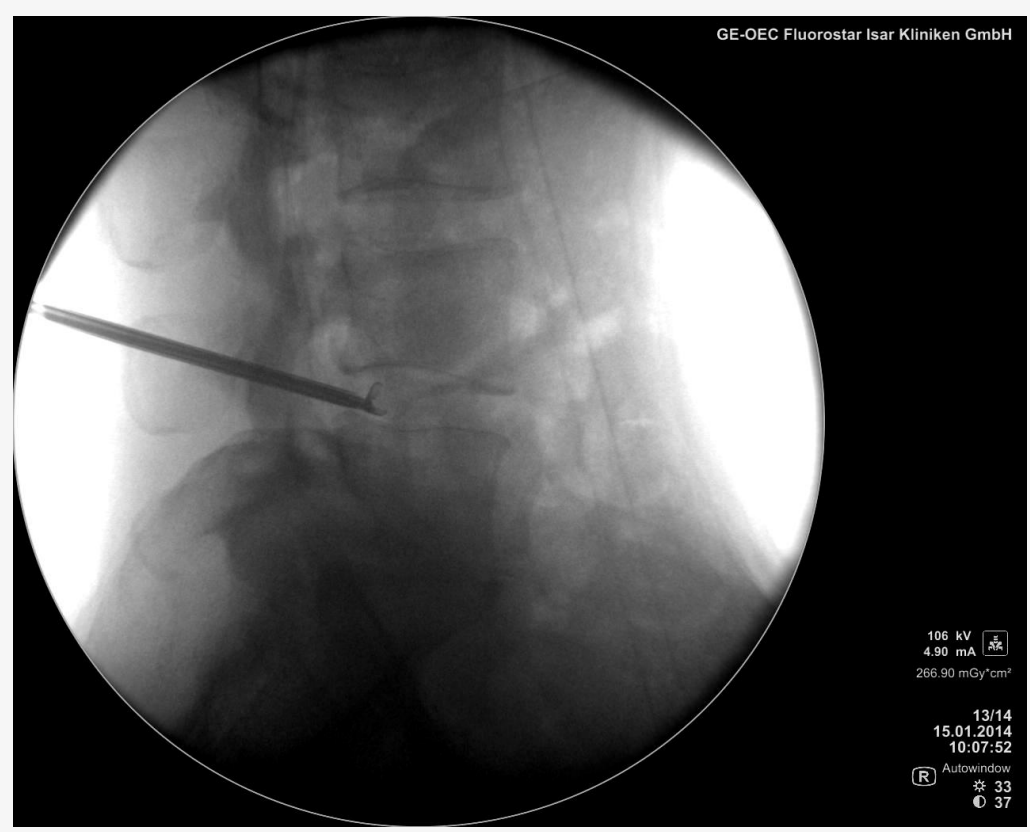

Fig. 1. Fluroscopic Picture

Saline is applied during the nucleus ablation to irrigate the system. The cannula is then pulled back into the outer annulus in order to shrink and stabilize the annulus with the Trigger-Flex using a special Bipolar Hemo waveform. Subsequent extraction of nucleus material is performed with the grasping forceps if necessary. ${ }^{34}$ Total delivery of energy to the nucleus and annulus should be limited to 6 applications of 6 seconds each, at a power setting of 25 on both Bipolar Turbo and Bipolar Hemo. It is important that the bipolar electrode does not touch the endplates during application.

For postsurgical care patients were given a de-lordotic brace for 4 to 6 weeks to reduce the posterior load in the disc during the healing, as well as stabilizing exercises after 2 weeks.

Primary endpoints of this survey were: subjective life improvement, Visual Analog Scale (VAS), SF-12 Health Survey, Macnab questionnaire, recurrence rate all compared to the earlier evaluated findings.

The secondary endpoints were operative complications.

\section{Statistical Methods}

Though we acknowledge that due to the small sample size statistical significance cannot be adequately determined, we nonetheless felt that by doing a statistical analysis we would obtain a baseline against which we can compare later data.

Explorative statistical data analyses was performed using Microsoft Access (Microsoft, Corp.,Redmond, WA) and SPSS software (version 16.0;SPSS Inc. Chicago, IL).

SPSS descriptive statistical analysis showed no normally distributed population $\mathrm{p}<0,05$ for both VAS leg and back pain (metric scale). The results obtained were analysed using: 
a) Wilcoxon test was used for statistical analysis -> dependent sample -> not normally distributed.

b) Kolmogorov-Smirnov test for dependent sample was used, with significance acceptance at $\mathrm{p}<0.001$

The author was not involved in the collecting or evaluation of this data.

\section{Results}

Of the 58 patients initially enrolled in this prospective outcome study clinical results from 47 patients $(81 \%)$ were available for review at 4 years. 9 patients could not be located, 1 patient died after 3 years for reasons unrelated to surgery.

Complications: As in the previous evaluations at 6 months and 2 years, no complications were reported.

Early Recurrence: Three patients $(6,4 \%)$ required additional microsurgical treatment less than six months after the index procedure. The timing of the onset of recurrent symptoms: 4 weeks $(n=1) ; 6$ weeks $(n=1)$; and eleven weeks $(n=1)$. Results in these three patients after the second procedure were deemed to be "very good".

Late Recurrence: Three patients (6.4\% of respondents) reported symptoms that required additional surgical treatment more than six months after the index procedure. The first of these three patients initially refused open fusion surgery and chose instead to try radiofrequency intradiscal decompression treatment for intractable back pain and so was enrolled in this study. Twelve months after the index procedure, this patient was treated with a two-level instrumented posterolateral fusion at L3-4 and L4-5 for continued axial back pain. The index procedure in the second patient included treatment at two-levels (L3-4 and L4-5). At 15 months after the index procedure, the patient experienced new symptoms and imaging confirmed reherniation of the in L4-5 disc on the same side as the index procedure. This patient was treated with endoscopic discectomy and was deemed to have a "good" result from the second procedure. The third patient showed a recurrent extruded disc herniation 24 month after the index procedure and underwent microdiscectomy without a significant change in his symptoms.

In $87 \%$ of the patients an open surgery was therefore successfully avoided. 


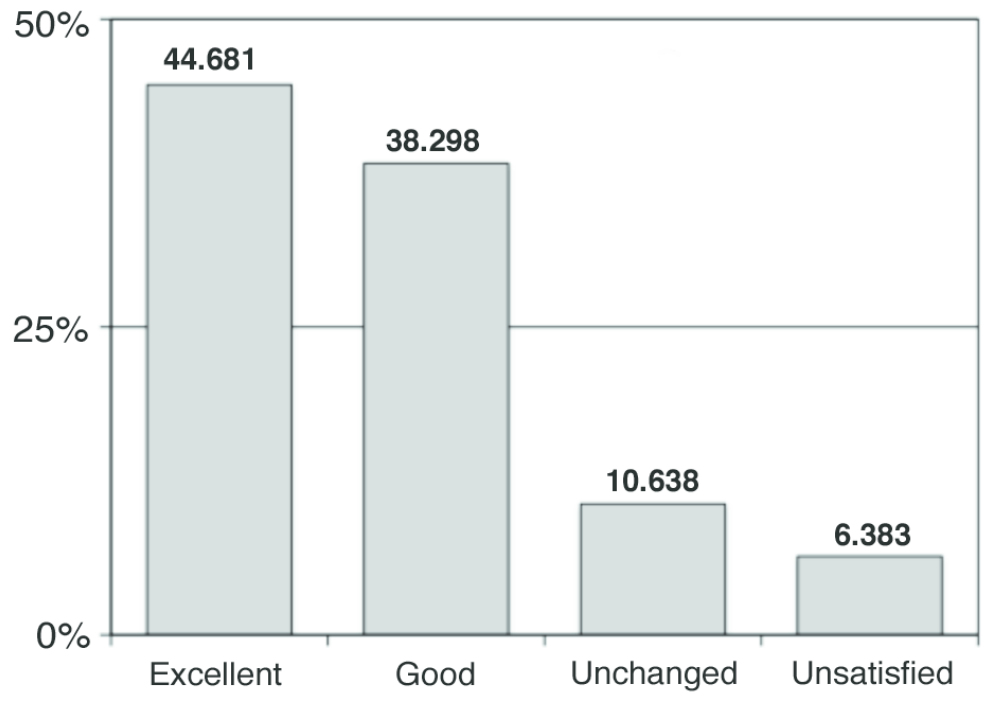

Fig. 2. Subjective patient satisfaction

VAS Back Pain: In 47 patients, mean VAS scores improved from a pre-treatment (baseline) of 8.6 (s.d. \pm 1.26 ) to 2.3 (s.d. \pm 2.32 ) four-years after the index procedure $(\mathrm{P}>0.0001)$ using Kolmogorov Smirnov test for dependent sample. Forty-six patients reported decreased VAS back pain scores; one patient reported increased VAS back pain score: pretreatment score 7 increased to 8 after four years.

VAS Leg Pain: 43 patients reported leg pain before the index procedure. The mean VAS leg pain score decreased from 7.8 (s.d. \pm 1.86 ) to 2.3 (s.d. \pm 2.77 ) at four-years after the index procedure $(\mathrm{P}>0.0001)$ using Kolmogorov Smirnov test for dependent sample. 42 patients reported decreased VAS leg pain scores; one patient in the recurrence group reported increased VAS leg pain score: pretreatment score 7 increased to 8 after four years. 


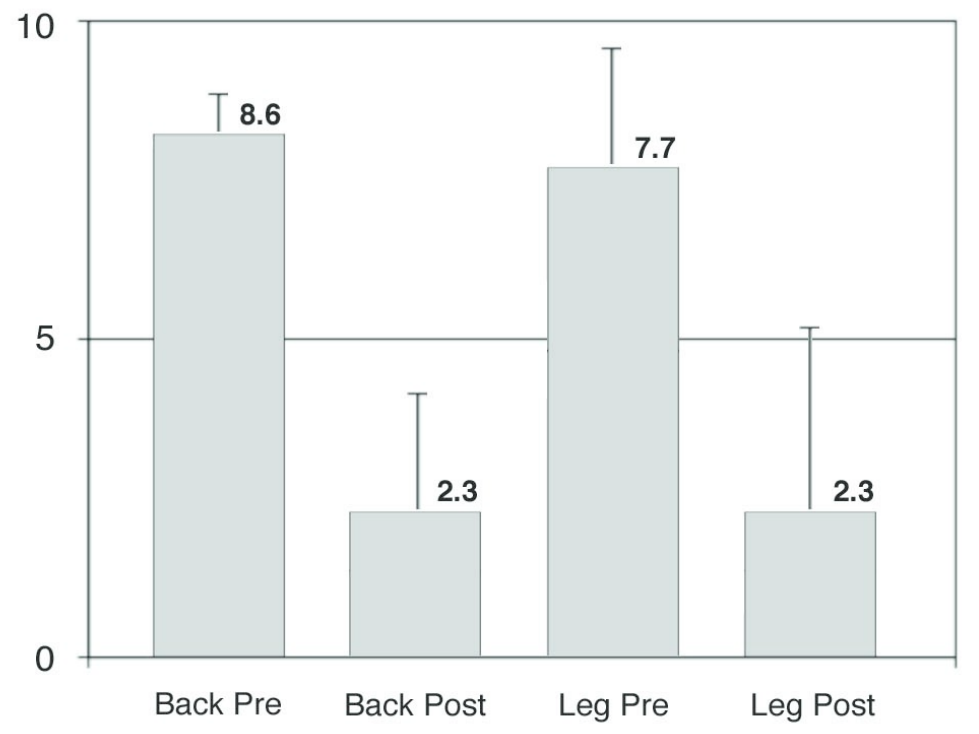

Fig. 3. VAS Back and Leg Pain

Patient Satisfaction: 47 patients reported their satisfaction with the index procedure after four years according to one of four categories: very satisfied ( $\mathrm{n}=21$ or $45 \%$ of respondents), satisfied ( $\mathrm{n}=18$ or $38 \%$ ), neutral ( $\mathrm{n}=5$ or $11 \%)$, or unsatisfied $(\mathrm{n}=3$ or $6 \%)$. Among three unsatisfied patients, two provided explanations for their disappointment: one experienced no relief of back pain after the index procedure and went on to be treated (unsuccessfully) with a two-level posterolateral instrumented fusion by a different surgeon. Another patient experienced a recurrent disc herniation (late reherniation) requiring microdiscectomy.

Lower Extremity Paresthesia: 40 patients reported lower extremity paresthesia before the index procedure. Patients reported lower extremity paresthesia four years after the index procedure according to one of four categories: fully recovered ( $n=25$ or $63 \%$ of respondents), improved ( $n=9$ or $23 \%)$, unchanged $(n=5$ or $13 \%)$, or worse $(n=1$ or $3 \%)$.

Lower Extremity Strength: 38 patients reported subjective lower extremity weakness before the index procedure. Patients reported lower extremity weakness four years after the index procedure according to one of four categories: fully recovered ( $n=18$ or $47 \%$ of respondents), improved $(n=13$ or $16 \%)$, unchanged $(n=6$ or $16 \%)$, or worse $(n=1$ or $3 \%)$.

Lifetime Satisfaction: live with this situation for the rest of your life $\mathrm{N}=47$

The quality of life score showed that $83 \%$ were satisfied with their current quality of life.

i) body capacity according to Macnab $\mathrm{N}=47$

In regards to SF-12, Macnab, patients also showed very steady and promising results. 
16 patients reported an excellent result with a fully regained body capacity (34\%), 19 patients reported a good result with minor restrictions (40.4\%), 10 patients reported a fair result with restrictions in their body capacity $(21.3 \%)$ and 2 patients reported poor results with no or insufficient improvement (4.3\%). According to the Macnab criteria a satisfactory result was also registered in $95.3 \%$.

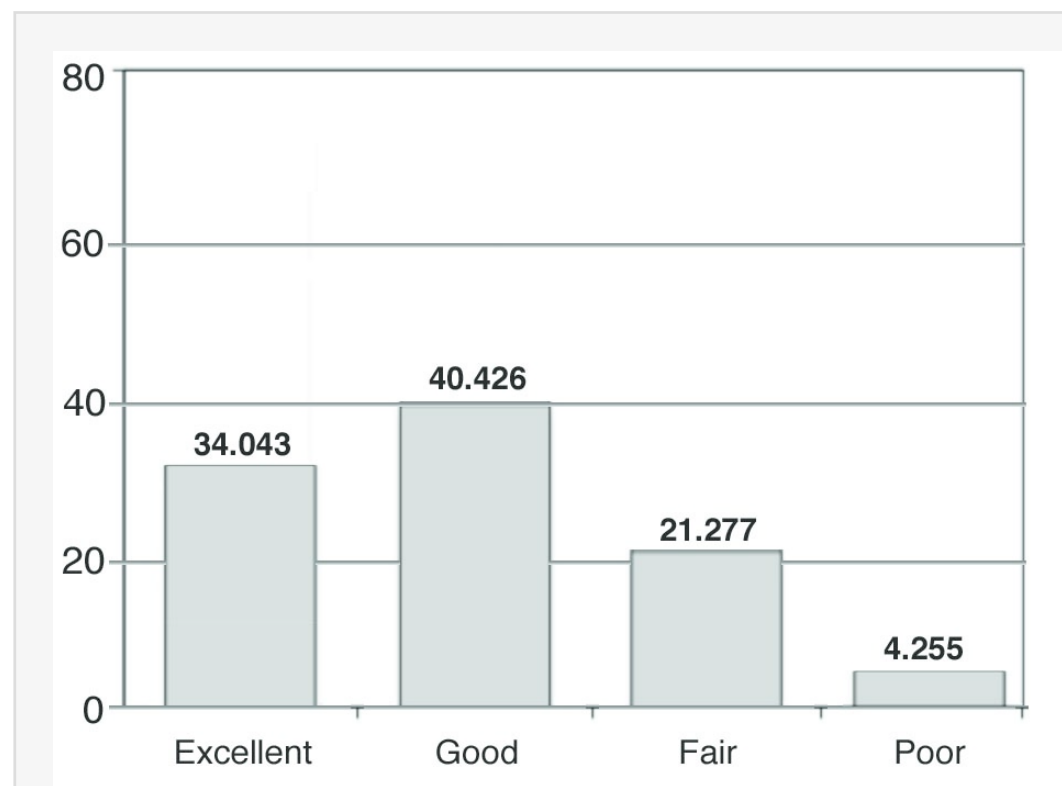

Fig. 4. Macnab at 4 yrs $(\mathrm{N}=47)$

\section{Discussion}

A previous evaluation of a multicenter study with the device under investigation showed very promising results at 6 months. ${ }^{35} \mathrm{~A}$ further investigation of patients from one site at two years confirmed these findings, showing no significant changes and a stable patient outcome. $^{28}$

The device used in this study is designed as a microtubular discectomy system to treat patients suffering from spinal pain caused by a disc herniation. It is the author's belief that this procedure should be placed in the cascade of treatment options for disc diseases: after failed conservative treatment and before open surgery.

If patients do not respond to conservative treatment and the symptoms do not allow them to follow their normal daily life activities within a certain time, very often a more aggressive therapy is demanded and considered.

Currently, patients presenting radicular low back pain not responding to conservative treatment are most commonly treated by open or microsurgical discectomy. If further degenerative changes are present maybe even a fusion surgery is required. As previously stated, there is a constant increase in the number of these surgeries in developed societies, which is associated with an increase of costs. Hout and Peul et al. evaluated the cost efficacy of early surgery to be an extremely expensive method from a health care economic perspective. ${ }^{36}$ 
The complications after a standard microsurgery have been described up to $8 \%$ with haematoma $0.05 \%$, incidential durotomy $3.3 \%$, nerve injuries $4.5 \%$, cauda equine syndroms $0.05 \%$ and epidural fibrosis. ${ }^{37}$

In addition to clinical outcomes, consideration of trauma caused by an approach and potential complications are important factors for assessing the value of a surgical method. All studies on Disc-FX or similar procedures have shown that the risk of any kind of complication is clearly decreased compared to open techniques.

While open surgery seems to be an unsatisfactory and too invasive treatment for patients with contained hernias, a small lateral approach can be a promising alternative if conservative therapy fails or symptoms are ongoing for a long time in these cases.

Using the extensive experiences from minimal invasive procedures, such as the endoscopic procedures, especially the SED System by Tony Yeung with the experience of thermal annuloplasty, the Disc-FX System was developed in the hope of addressing the unsatisfactory clinical outcomes for contained herniations. The positive effects of high radiofrequency have been proven in endoscopic spine surgery as well in neurosurgical applications already. Additionally, the knowledge gained from single percutaneous applications like Nucleo- and annuloplasty was used. ${ }^{38,39,40}$ As shown in the full endoscopic techniques, the combination of different steps improves the outcome. ${ }^{41}$ Other authors have also demonstrated that a combination of different procedures can be helpful. ${ }^{42,43,44,45,46,47,48}$

The technical aspects and the basic surgical technique for this procedure have been very well investigated in several independent pre-clinical testings. ${ }^{33}$ However to prove a technique to be equivalent to the accepted existing treatment options, outcome and the patient's satisfaction in a long period are important. Comparing the outcomes, reoperation and complication rates to the standard open surgery, the existing study shows that the combination procedure causes less trauma, delivers significant pain relief and should be considered as an alternative treatment in the presence of contained hernias. ${ }^{15,16,50}$

Compared to the published literature of results for open surgery in the presence of contained hernias, this technique seems to be more than equivalent. A direct comparison of this microtubular technique to open surgery for discal hernias has been published by Liao Xiang. ${ }^{51}$ The paper quotes that at 12 months both groups showed comparable outcomes in VAS and ODI.

Looking at an overview of open as well as percutaneous studies, this technique demonstrates equal results to open techniques for contained hernias and superiority to percutaneous nonendoscopic needle based procedures regarding outcomes, complications and recurrence rates.

Table 2.

\begin{tabular}{|l|l|l|l|l|}
\hline Study (Reference) & Recurrence Rate & Years & Outcome & Type of surgery \\
\hline Hellinger 2014 (32-33) & $\begin{array}{l}6.3 \% \text { short }<3 \text { Mo 6.3\% } \\
\text { long }>3 \mathrm{M}\end{array}$ & 4 yrs & $83.0 \%$ & DiscFX \\
\hline Hellinger, Feldmann 2010 (34) & $4 \%$ & $\begin{array}{l}6 \text { Months 2 } \\
\text { yrs }\end{array}$ & $82.2 \%$ & DiscFX \\
\hline Jannson et al. 2004 (16) & $10 \%$ & 10 yrs & only reoperation & Microsurgery \\
\hline
\end{tabular}




\begin{tabular}{|c|c|c|c|c|}
\hline Häkkinen et.al 2007 (48) & $11 \%$ & $5 \mathrm{yrs}$ & only reoperation & Microsurgery \\
\hline Ostermann et al. 2003 (49) & $14 \%$ & $\begin{array}{l}1987-1998 \\
N=35.309\end{array}$ & only reoperation & $\begin{array}{l}\text { Lumbar open dorsal } \\
\text { Discectomy }\end{array}$ \\
\hline Carragee (31) & $15 \%$ & $2-6 \mathrm{yrs}$ & $\begin{array}{l}24 \% \text { for contained } \\
\text { hernias }\end{array}$ & $\begin{array}{l}\text { Open dorsal } \\
\text { Discectomy for } \\
\text { sciatica }\end{array}$ \\
\hline $\begin{array}{l}\text { Hoogland / Gibson / Iprenburg / Ruetten / } \\
\text { Tsou (17-19-22-23-24-48) }\end{array}$ & $\begin{array}{l}6.9 \%(\mathrm{HO}) 8 \%(\mathrm{G}) 13 \%(\mathrm{I}) \\
6.3 \%(\mathrm{R}) 15 \%(\mathrm{~T})\end{array}$ & $2-4 \mathrm{yrs}$ & $75-89 \%$ & ENDOSCOPY \\
\hline Hoogland (24) & $\begin{array}{l}1.6 \% \text { Hoogland Endo mit } \\
\text { Chemo }\end{array}$ & $2 \mathrm{yrs}$ & $\begin{array}{l}\text { Endo Group } 85.4 \% \text { Endo } \\
+ \text { Chymo } 93.3 \%\end{array}$ & $\begin{array}{l}\text { ENDOSCOPY with } \\
\text { Chymo }\end{array}$ \\
\hline Manchikanti et al. 2009 (53) & & $2 \mathrm{yrs}$ & $56 \%$ & Nucleoplasty \\
\hline Choy, Tassi,Hellinger S.H. Lee (52) & $5 \%$ & up to $8 \mathrm{yrs}$ & $70-89 \%$ & $\begin{array}{l}\text { Laserdiscus- } \\
\text { decompression }\end{array}$ \\
\hline Wardlaw (54) & $10 \%$ & $\begin{array}{l}1 / 10-13 / \\
24-27 \mathrm{yrs}\end{array}$ & $95 \% / 72 \% / 63 \%$ & Chymopapaine \\
\hline
\end{tabular}

Compared to the previous investigation at 2 years, this study shows no significant change in outcome at 4 years. Furthermore, $82 \%$ of the patients continued to have a significant improvement in leg pain. The improvement in low back pain as an expression of discogenic pain for $87 \%$ of the patients after 4 years was unexpected. It indicates that a less traumatizing approach to the lumbar spine combined with the proven effects of radiofrequency have a positive impact on this problem and can help to avoid open surgery or even a fusion. ${ }^{55}$ Huang et al. have shown that the posterolateral minimal invasive approach has a lower systemic response in postsurgical metabolism. ${ }^{56}$ Additionally, the opportunity to do this procedure under local anaesthesia gives the patient a diminished peri- and postoperative stress. A faster recovery, mobilization and less postoperative pain are advantageous to the patients undergoing this procedure.

Other studies to extend the statistic power of this limited number of patients are on their way to underline these findings.

\section{Conclusion}

Overall, the results from this 4 year study are very encouraging and qualify the safe continuous use of the technique in carefully selected patients with low back and radicular pain of discogenic origin. Comparing the outcomes, reoperation and complication rates to open surgery, the presented procedure ( $83 \%$ satisfaction rate, $6.3 \%$ late reoperation, no complications) shows no inferiority, causes less surgical trauma, delivers significant pain relief and should be considered as an option in the presence of contained hernias. The intention is to give the patient a chance to avoid an open surgery and leave the dorsal approach virgin.

\section{References}

1. Ehrlich G, Low back pain. Bull World Health Organ. 2003; 81 (9):p. 671-6

2. Weinstein JN, Lurie JD, Olson PR et al., United States' trends and regional variations in lumbar spine surgery:1992-2003. Spine (Phila Pa 1976). 2006; 31(23): p.2707-14

3. Klauber J, Geraedts m, Friedrich J, et al., Krankenhausreport 2013: Mengendynamik: Mehr Nutzen?. Schattauer. 2012; p.117 -125, image 7-1 Datenquelle AOK HEALTH REPORT 2013

4. Niethard, Fritz, Endoprothetik und Wirbelsäuleneingriffe: Uneinheitliches Versorgungsgeschehen. Deutsches Ärzteblatt .2013; 110(27-28): A-1362 / B-1197 / C-1181 
5. Hofstee DJ, Gijtenbeek JM, Hoogland PH, et al. Sciatica Trial: randomized controlled study of bed rest and physiotherapy for acute sciatica. J Neurosurgery. 2002; 96: p.45-49.

6. Vroomen PC, Krom MC, Slofstra PD, et al., Conservative treatment of sciatica: a systematic review. J Spinal Disord. 2000;13: p.463-469.

7. Gracey JH, McDonough SM, Baxter SD, Physiotherapy management of low back pain: a survey of current practise in Northern Ireland. Spine (Phila PA 1976). 2002; Feb 15;27(4):406-11

8. Harte AA., Gracey JH, Baxter GD, Current use of lumbar traction in the management of low back pain: results of a survey of physiotherapists in the United Kingdom. Arch Phys Med Rehabil. 2005; 86(6): p.1164-9

9. Armstrong MP, Mc Donough SM, Baxter SD, Clinical guidelines versus clinical practise in the management of low back pain. Int. Journal of Clinical Practise. 2003; 57(1): p.9-13

10. Yeung AT, Gore S. In-vivo Endoscopic Visualization of Patho-anatomy in Symptomatic Degenerative Conditions of the Lumbar Spine II: Intradiscal, Foraminal, and Central Canal Decompression. Surg. Technol .International. 2011; Dec 1;XXI:299-319.

11. Postacchini F, Management of herniation oft he lumbar disc. J Bone and Joint Surgery Br. 1999; 81(4), p.567-76

12. Macnab I, Negative disc Exploration. An analysis of the causes of nerve root involvement in sixty eight patients. J. of Bone Joint Surg. Am.. 1971; 54 (5): p. 891-903

13. Olmarker K, Rydevik B, Nordborg C, Autologous nucleus pulposus induces neurophysiologic and histologic changes in porcine cauda equina nerve roots. Spine (Phila Pa 1976). 1993; 18(11):p. 1425-32

14. Hall LT:, Esses SI, Noble PC et al, Morphology of the lumbar vertebral endplates. Spine (Phila Pa1976). 1998; 23 (14): p. 1517-22

15. Fagan AB, Sarvestani G, Moore RJ, et al, Innvervation of annular tears: an experimental animal study. Spine (Phila Pa 1976). 2010; 35(12):p .1200-5

16. Atlas SJ, Deyo RA, Keller RB, et al, Long term outcomes of surgical and nonsurgical management of sciatica secondary to a lumbar disc herniation: 10 years results from the maine lumbar spine study. Spine Journal. 2005; Apr; 5;30 (8):p.927-35

17. Jannsson KA, Nemeth G, Granath F, et al., Surgery for herniation of a lumbar disc in Sweden between 1987 and 1999 an analysis of 27576 operations. JBJS. 2004; Vol86-B, 6, p.841-7

18. Ruetten S., Komp M., Merk, H., et al., Full-endoscopic interlaminar and transforaminal lumbar discectomy versus conventional microsurgical technique: a prospective, randomized, controlled study. Spine Journal. 2008; Apr 20,33(9); p. 931-9.

19. Maroon JC, Current concepts in minimally invasive discectomy. Neurosurgery. 2002; Nov; 51(5):p.137-45

20. Yeung AT, Tsou PM, Posterolateral Endoscopic Exicions for Lumbar Disc Herniation: Surgical Technique, Outcome and Complications in 307 Consecutive Cases. Spine Journal (Phila Pa 1976). 2002; April 27; 7: p. 722-731

21. Yeung AT, Endoscopic spinal surgery: What future role?. The Journal of Musculoskeletal Medicine. 2001; Nov; Vol 18 (11): p. 518-28 
22. Ruetten S, Komp M, Hahn P, et al., Decompression of lumbar lateral spinal stenosis: full endoscopic, interlaminar technique. Operating Orthopaedic Traumatology. 2013; Feb 25(1): p. 31-46

23. Ruetten S, Full endoscopic operations of the spine in disk herniations and spinal stenosis. Surg. Technol. Int.. 2011; Dec; XXI: p. 284-298

24. Hoogland T, Schubert M, Miklitz B, et al. Endoscopic transforaminal discectomy for recurrent lumbar disc herniation: a prospective, cohort evaluation of 262 consecutive cases. Spine (Phila PA). 2008; Apr 20; 33(9); p. 973-8

25. Hoogland T, Schubert M, Miklitz B, et al., Transforaminal posterolateral endoscopic discectomy with or without the combination of a low dose chymopapain: a prospective randomized study in 280 consecutive cases. Spine (Phila Pa). $2006 \mathrm{Nov}$ 15; 31(24):p. 890-7

26. PC Gerszten, Smuck M, Rathmell JP, et al., Plasma disc decompression compared with fluoroscopic guided transforaminal epidural steroid injections for symptomatic contained lumbar disc herniation: a prospective, randomized, controlled trial. J. Neurosurg Spine. 2010;12; 357-71

27. Assietti R, Morosi M, Migliaccio G, et al., Treatment of discogenic low back pain with Intradiscal Electrothermal Therapy (IDET): 24 months follow-up in 50 consecutive patients. Acta Neurochir Suppl. 2011;108:103-5. doi: 10.

28. Barende GA, van den Berg SG, Kessel AH, et al., Randomized controlled trial of percutaneous intradiscal radiofrequency thermocoagulation for chronic discogenic pain. Lack of effect from a 90 second 70C lesion. Spine (Phila Pa 1976). 2001; 26(3):p. 287-92

29. Houpt JC, Conner ES, MacFarland EW, Experimental study of temperature distribution and thermal transport during radiofrequency current therapy of the intervertebral disc. Spine (Phila PA). 1996; 21(15):p.1808-13

30. Hall LT, Essel SI, Noble PC, et al., Morphology of the lumbar vertebral endplates. Spine (Phila PA 1076). 1998; 23(14):p. 1517-23

31. Weinstein JN, Lurie JD, Tosteson TD, et al., Surgical vs nonoperative treatment for lumbar disk herniation: the Spine Patient Outcomes Research Trial (SPORT) observational cohort. JAMA. 2006; 296: p. 2451-9

32. Carragee EJ, Han MY, Suen PW, et al., Clinical outcomes after lumbar discectomy for sciatica: the effect of fragment type and annular competence. J Bone Joint Surg Am. 2003; Jan; 85-A(1): p.102-8

33. Hellinger S, Liao X, Mermelstein L, et al., Radiofrequency assisted lumbar semi endoscopic manual discectomy using Disc-FX System- Preliminary results of various ongoing clinical outcome studies worldwide. Europ. Musculoskeletal Review. 2011; Winter Vol 6(4), p.265-71

34. Hellinger S, Disc-FX A treatment for discal pain syndromes combining a manual and radiofrequency assisted posterolateral decompressive nucleotomy. Europ. Musculoskeletal Review. 2011; Summer Vol 6(2), p.100-04

35. Feldman A, Hellinger S, DISC FX- A new combination procedure for disc surgeryradiowave ablation, annulus decompression and mechanic nucleotomy in one- basics and a prospective study. IJMIST. 2008; Suppl.1(1)[2

36. Hout WB, Peul WC, Koes BW, et al., Prolonged conservative care versus early surgery in patients with sciatica from lumbar disc herniation: cost-utility analysis alongside a randomised controlled trial. BMJ. 2008; 336:p. 1351-1354 
37. Li SW, Yin HP, Wu YM,et al., Analysis of intraoperative complications of microendoscopic discectomy and corresponding preventive measures. Zhongou $\mathrm{Gu}$ Shang. 2013; March 26(3):218-21

38. Singh V, Priyano C, Liao K, et al., Percutaneous disc decompression using coblation (nucleoplasty) in the treatment of chronic discogenic pain. Pain Physician. 2002; July 5(3):p.250-9

39. Manchikanti L, Falco FJ, Benyamin RM, et al., An update of the systematic assessment of mechanical lumbar disc decompression with nucleoplasty. Pain Physician. 2013; Apr. 16(2Suppl): p. 25-54

40. Saal JA, Saal JS, Intradiscal electrothermal treatment for chronic discogenic low back pain: prospective outcome study with a minimum 2 years follow up. Spine (Phila Pa1976). 2002; May1 27(9):p. 966-974

41. Tsou PM, Yeung CA, Yeung AT, Posterolateral transforaminal selective endoscopic discectomy and thermal annuloplasty for chronic lumbar discogenic pain: a minimal access visualized intradiscal surgical procedure. Spine Journal, 2004; 4(5); p.564-73

42. Ruano A, Rodrigues B. Nucleoplasty treatment of symptomatic disc herniation [ABSTRACT]. EFORT 2003 6th Congress of the European Federation of Orthopaedics and Traumatology Helsinki, Finland. P5040

43. Kyeong HS, Sang-Hoo L, et al., Percutaneous endoscopic manual and laser discectomy for herniated lumbar discs. Lasers and Electro Optics. 1999; CLEO / The Pacific Rim Conference APOS Vol 4;p. 1169-1170

44. Yeung AT, The evolution and advancement of endoscopic foraminal surgery: one surgeons's experience incorporating adjunctive technologies. Spine Arthroplasty Journal. 2007; 1(3);p.1-10

45. Chiu JC, Evolving transforaminal endoscopic microdecompression for herniated lumbar discs and spnal stenosis. Surg Technol Int. 2004; 13: p. 276-86

46. Lew SM, Mehalic TF, Fagone KL, Transforaminal percutneous endoscopic discectomy in the treatment of far lateral and foraminal lumbar disc herniations. J. Neuosurg.. 2001; 94(supl.2):p 216-20

47. Mayer HM, Brock M, Percutaneous endoscopic discectom: Surgical technique and preliminary results compared to microsurgical discectomy. J.Neurosur.. 1993; Feb; 78(2): p. 216-25

48. Lee SH, Lee SJ, Park KH, et al., Vergleich einer Kombination von perkutaner manueller und endosckopischer Laserdiskektomie mit Chemonukleolyse und automatisierter Nukleotomie. Orthopädie. 1996; 25: p. 49-55

49. Häkkinen A, Kiviranta I, Neva MH, et al., Reoperations after first lumbar disc herniation surgery; a special interest on residives during a 5-year follow-up. BMC Musculoskelet Disord. 2007; Jan 9;8:2.

50. Osterman H, Sund R, Seitsalo, et al., Risk of multiple reoperations after lumbar discectomy: a population based study. Finland Spine. 2003; 28(6):p. 621-7

51. Liao X, Jiang J, Xiong DL, et al., The comparison of clinical outcomes of percutaneous lumbar discectomy with DiscFX System with fenestration and decompression for contained lumbar disc herniation (LDH) with radicular pain. Chinese journal of pain medicine. 2011; $(17,1)$.

52. Choy DS, Hellinger J, Hellinger S, Tassi GP et al., 23rd Anniversary of Percutaneous Laser Disc Decompression (PLDD). Photomed Laser Surg. 2009; Aug;27(4):535-8.

53. Manchikanti L, Derby R, Helm S, et al., A systematic review of mechanical lumbar disc decompression with nucleoplasty. Pain Physician That. 2009; 12:561-572. 
54. Wardlaw D, Rithchie IK, Sabboubeh AF, et al., Prospective randomized trial of chemonucleolysis compared with surgery for soft disc herniation with 1 year, intermediate, and long-term outcome:part !: the clinical outcome . Spine (Phila Pa 1976). 2013; Aug 1;38(17):E1051-7

55. O’Neil, Liu J, Leibenber S, et al., Percutaneous Plasma Decompression Alters Cytokine Expression In Injured Porcine Intervertebral Discs. The Spine Journal. 2004; (4): p. 115-8

56. Huang TJ, Hsu RW, Li YY, et al., Less systemic cytokine response in patients following microendoscopic versus open lumbar discectomy.Journ. Orhtop. Res.. 2005; March 23(2):p. 406-11

\section{Disclosures}

Dr. Hellinger has received honoraria for speaking and teaching from elliquence LLC.

\section{Corresponding Author}

Stefan Hellinger MD, ISAR Clinic Munich, Sonnenstr.24, 80331 München, Germany. hellinger@gmx.de

Copyright (C) 2014 ISASS - International Society for the Advancement of Spine Surgery. To see more or order reprints or permissions, see http://ijssurgery.com. 